\title{
Role of Adjuvant Treatment in High-risk Patients Following Resection for Gallbladder Cancer
}

\author{
YOUNGHEE PARK ${ }^{1}$, KIRYUN KIM ${ }^{2}$, HAE JIN PARK ${ }^{3}$, HA-JUNG CHUN ${ }^{3}$, DONGHO CHOI ${ }^{4}$ and KYUBO KIM ${ }^{5}$ \\ ${ }^{1}$ Department of Radiation Oncology, Soonchunhyang University Seoul Hospital, Seoul, Republic of Korea; \\ ${ }^{2}$ Hanyang University College of Medicine, Seoul, Republic of Korea; \\ ${ }^{3}$ Department of Radiation Oncology, Hanyang University College of Medicine, Seoul, Republic of Korea; \\ ${ }^{4}$ Department of Surgery, Hanyang University College of Medicine, Seoul, Republic of Korea; \\ ${ }^{5}$ Department of Radiation Oncology, Ewha Womans University College of Medicine, Seoul, Republic of Korea
}

\begin{abstract}
Aim: To identify prognostic factors for surgically resected gallbladder cancer (GBC). Patients and Methods: Medical records of 66 patients with GBC undergoing potentially curative resection between 2001 and 2017 were retrospectively reviewed. Results: After a median follow-up of 39.9 months (range=0.5-216.4 months), 22 locoregional recurrences and 25 distant metastases occurred. Adjuvant radiotherapy and adjuvant chemotherapy failed to prove efficacy in all patient groups. In patients with stage III-IV $G B C$, adjuvant chemotherapy showed a marginally positive effect on locoregional control $(p=0.064)$, and was significantly beneficial for overall survival $(p=0.040)$, and adjuvant treatment improved both locoregional control and overall survival ( $p=0.029$ and $p=0.005$, respectively). On multivariate analysis, a negative resection margin was a significant prognostic factor for superior local control, and disease-free and overall survival ( $p=0.003, p=0.010$ and $p=0.005$, respectively) and adjuvant treatment was associated with improved overall survival ( $p=0.018)$. Conclusion: Adjuvant treatment is recommended for patients with stage III-IV GBC following curative surgical resection.
\end{abstract}

Gallbladder cancer (GBC) is a rare disease but its incidence in Korea is relatively high when compared to Western countries and it constitutes the sixth leading cause of cancer death in Korea $(1,2)$. Complete surgical resection is supposed

This article is freely accessible online.

Correspondence to: Hae Jin Park, MD, Ph.D., Department of Radiation Oncology, Hanyang University College of Medicine, 2221 Wangsimni-ro, Seongdong-gu, Seoul 04763, Republic of Korea. E-mail: haejinpark@hanyang.ac.kr

Key Words: Gallbladder cancer, adjuvant chemotherapy, adjuvant radiotherapy, adjuvant treatment, prognostic factor. to be the curative treatment for patients with early-stage GBC, but most patients are diagnosed with advanced disease which is not amendable to surgical resection (3). Moreover, even after curative surgical resection, locoregional recurrences (LRR) and distant metastases (DM) are common, which confer a dismal prognosis $(4,5)$. To improve prognosis, the need for adjuvant treatments has been suggested. Previous studies have reported the outcome of adjuvant treatments such as chemotherapy, radiotherapy (RT), or chemoradiotherapy (CRT) after surgical resection for GBC (6-9). However, because of the rarity of GBC, randomized studies are not readily available and the results of most studies are contradictory because they included a heterogeneous group of patients. Therefore, the benefit of adjuvant treatment after surgical resection for GBC remain unclear.

In this study, we investigated prognostic factors and evaluated the benefit of adjuvant treatment for patients undergoing curative surgical resection of GBC.

\section{Patients and Methods}

Patients. Medical records of patients who underwent curative surgical resection for GBC between June 2001 and September 2017 were retrospectively reviewed. The inclusion criteria for this study were as follows: i) Pathologically proven adenocarcinoma, ii) T2 or higher disease, iii) no distant metastasis, iv) no preoperative chemotherapy, v) no previous history of RT to the abdomen, and vi) no double primary cancer. Patients who developed recurrences before planned adjuvant therapy were excluded. After exclusion of ineligible patients, a total of 66 patients were included in this study. The study protocol was approved by the Institutional Review Board (approval number: 2019-09-029).

Clinicopathological and laboratory data. The clinicopathological data including age, gender, histology, stage according to the eighth edition of the American Joint Committee on Cancer classification (10), histological findings, type of surgery, and adjuvant treatment were collected. Laboratory parameters included complete blood cell count and serum carbohydrate antigen 19-9 (CA 19-9). The 
neutrophil to lymphocyte ratio and platelet to lymphocyte ratio were calculated as the absolute neutrophil or platelet count divided by the absolute count of lymphocytes, respectively.

Treatment. After surgical resection, adjuvant treatment was decided according to the physician's discretion depending on the risks for recurrence. For patients receiving RT, the radiation dose was 30-45 Gy (1.6-3.0 Gy/fraction, 5 days per week) in 10-25 fractions. Adjuvant chemotherapy was administered either alone or as CRT using 5-fluorouracil (5-FU)- or gemcitabine-based regimens.

Study endpoints and statistical analysis. Locoregional recurrencefree (LRRFS), distant metastasis-free (DMFS), disease-free (DFS) and overall (OS) survival were calculated from the date of surgical resection. LRR was defined as a relapse in the tumor bed or regional lymph node area. The actuarial survival rates were calculated using Kaplan-Meier method and the differences were compared with a log-rank test. For multivariate analysis, Cox proportional-hazards model was used. All statistical analyses were performed using SPSS software (release 18.0.1. SPSS Inc. Chicago, IL, USA).

\section{Results}

Baseline characteristics. Of the 66 patients included in this study, there were 29 males and 37 females. The median age was 64 years (range $=45-87$ years). Simple cholecystectomy was performed in 20 patients $(30.3 \%)$ and extended cholecystectomy in $46(69.7 \%)$. The resection margin status was negative (R0) in 54 patients $(69.2 \%)$, with microscopic involvement (R1) in eight (10.3\%) and not evaluated in four $(5.1 \%)$. Thirty-eight patients $(57.6 \%)$ had pT2 stage GBC, $26(39.4 \%)$ pT3 and two patients (3.0\%) T4. Lymph node involvement was found in 30 patients $(45.5 \%)$ and overall stage was II in 26 patients $(39.4 \%)$, III in $35(53.0 \%)$ and IV in five $(7.6 \%)$. Perineural invasion, lymphatic invasion and vascular invasion were present in $27(40.9 \%), 34$ $(51.5 \%)$ and 20 patients $(30.3 \%)$, respectively. The median value for serum CA 19-9 was $17.3 \mathrm{ng} / \mathrm{ml}$ (range=0.6-1,556.0 $\mathrm{ng} / \mathrm{ml}$ ) at diagnosis and $8.3 \mathrm{ng} / \mathrm{ml}$ (range $0.6-3,487.0 \mathrm{ng} / \mathrm{ml}$ ) after resection.

Adjuvant treatments were administered to 29 patients (43.9\%), and of these, six received CRT, 18 received chemotherapy alone, four received RT alone and one patient had concurrent CRT followed by chemotherapy. For concurrent CRT, 5-FU-based (five out of seven patients, $71.4 \%$ ) or gemcitabine-based (two of seven patients, 28.6\%) regimens were administered with $\mathrm{RT}$. In patients receiving adjuvant chemotherapy alone, four $(22.2 \%)$ were treated with a 5-FU-based regimen, eight $(44.4 \%)$ with a gemcitabinebased regimen and six (33.3\%) with 5-FU and gemcitabine.

Treatment outcome and patterns of failure. After a median follow-up of 39.9 months (range=0.5-216.4 months), 34 patients $(51.5 \%)$ had died, and the 5-year OS rate was $54.0 \%$ (Figure 1). Thirty patients developed recurrences: 22 LRRs

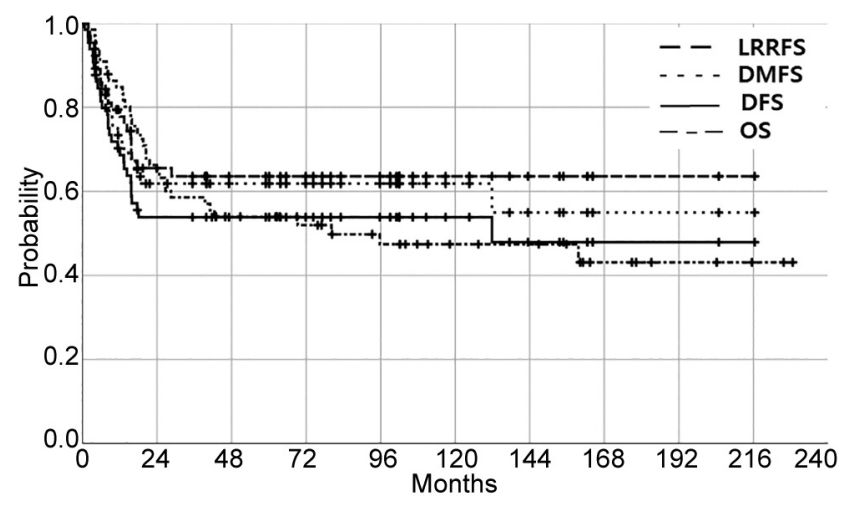

Figure 1. Locoregional recurrence relapse-free (LRRFS), distant metastasis-free (DMFS), disease-free (DFS), and overall (OS) survival curves for the whole study cohort.

and $25 \mathrm{DMs}$ as initial recurrences. The most common site of DM was the liver $(n=15,60.0 \%)$ followed by the peritoneum $(n=10,40.0 \%)$, lung $(n=3)$, non-regional lymph node $(n=3)$, bone $(n=1)$, and pelvic cavity $(n=1)$. The 5 -year DFS, LRRFS and DMFS rates were $53.9 \%, 63.6 \%$ and $61.8 \%$, respectively.

Prognostic factors. The results of univariate analysis for DFS, LRRFS, DMFS and OS are summarized in Table I. TStage, N-stage, overall stage, residual disease status, perineural invasion, lymphatic invasion and postoperative CA 19-9 level were significant prognostic factors for DFS, LRRFS, DMFS and OS ( $p<0.05$ for each). Adjuvant chemotherapy and RT were not associated with outcomes but patients who received adjuvant treatment (either chemotherapy or RT) tend to show improved DFS ( $p=0.067)$. On multivariate analysis, overall stage and postoperative CA 19-9 level were significant prognostic factors for all of the treatment outcomes ( $p<0.05$ for each, Table II). Residual disease status was a significant prognostic factor for LRRFS, DFS and OS.

When evaluating only patients with stage III-IV (Table III), univariate analysis showed that age, N-stage, overall stage (III vs. IV), residual disease status, postoperative CA 19-9 level, and adjuvant treatment were significant prognostic factors for LRRFS ( $p<0.05$ for each) and adjuvant chemotherapy showed marginally significant association with LRRFS $(p=0.064)$. Stage III, postoperative CA 19-9 level $<37 \mathrm{U} / \mathrm{ml}$, adjuvant treatment and adjuvant chemotherapy were all associated with improved OS. None of the factors showed a significant association with DMFS. On multivariate analysis (Table IV), residual disease was a prognostic factor for poorer LRRFS, DFS and OS $(p<0.05$ for each) and adjuvant treatment was significantly associated with improved OS (hazard ratio $=3.50$, 95\% confidence interval=1.24-9.90, $p=0.018$; Figure 2). 
Table I. Univariate analysis of locoregional recurrence-free (LRRFS), distant metastasis-free (DMFS), disease-free (DFS) and overall (OS) survival for the whole patient cohort.

\begin{tabular}{|c|c|c|c|c|c|c|c|c|c|c|}
\hline \multirow[b]{2}{*}{ Variable } & \multirow[b]{2}{*}{ Subgroup } & \multirow[b]{2}{*}{$\mathrm{n}=66(\%)$} & \multicolumn{2}{|c|}{ LRRFS } & \multicolumn{2}{|c|}{ DMFS } & \multicolumn{2}{|c|}{ DFS } & \multicolumn{2}{|c|}{ OS } \\
\hline & & & Event (n) & $p$-Value & Event (n) & $p$-Value & Event (n) & $p$-Value & Event (n) & $p$-Value \\
\hline \multirow[t]{2}{*}{ Age } & $<65$ Years & $35(53.0)$ & 8 & 0.017 & 13 & 0.462 & 13 & 0.044 & 14 & 0.008 \\
\hline & $\geq 65$ Years & $31(47.0)$ & 14 & & 12 & & 17 & & 20 & \\
\hline \multirow[t]{2}{*}{ Gender } & Male & $29(43.9)$ & 12 & 0.323 & 12 & 0.653 & 15 & 0.526 & 15 & 0.822 \\
\hline & Female & $37(56.1)$ & 10 & & 13 & & 15 & & 19 & \\
\hline \multirow[t]{3}{*}{ T-Stage } & pT2 & $38(57.6)$ & 7 & 0.001 & 9 & 0.004 & 11 & $<0.001$ & 14 & $<0.001$ \\
\hline & pT3 & $26(39.4)$ & 14 & & 15 & & 18 & & 18 & \\
\hline & pT4 & $2(3.0)$ & 1 & & 1 & & 1 & & 2 & \\
\hline \multirow[t]{3}{*}{ N-Stage } & pNO & $36(54.5)$ & 5 & $<0.001$ & 8 & $<0.001$ & 10 & $<0.001$ & 14 & 0.002 \\
\hline & $\mathrm{pN} 1$ & $26(39.4)$ & 13 & & 13 & & 16 & & 16 & \\
\hline & $\mathrm{pN} 2$ & $4(6.1)$ & 4 & & 4 & & 4 & & 4 & \\
\hline \multirow[t]{3}{*}{ Overall stage } & II & $26(39.4)$ & 1 & $<0.001$ & 3 & $<0.001$ & 4 & $<0.001$ & 7 & $<0.001$ \\
\hline & III & $35(53.0)$ & 17 & & 18 & & 22 & & 22 & \\
\hline & IV & $5(7.6)$ & 4 & & 4 & & 4 & & 5 & \\
\hline \multirow{3}{*}{$\begin{array}{l}\text { Residual } \\
\text { disease } \\
\text { status }\end{array}$} & R0 & $54(81.8)$ & 15 & $<0.001$ & 18 & 0.036 & 21 & 0.004 & 25 & 0.012 \\
\hline & $\mathrm{R} 1$ & $8(12.1)$ & 6 & & 5 & & 6 & & 6 & \\
\hline & Unknown & $4(6.1)$ & 1 & & 2 & & 3 & & 3 & \\
\hline \multirow{4}{*}{$\begin{array}{l}\text { Tumor } \\
\text { differentiation }\end{array}$} & Well & $8(12.1)$ & 2 & 0.134 & 2 & 0.285 & 2 & 0.029 & 3 & 0.072 \\
\hline & Moderate & $36(54.5)$ & 10 & & 12 & & 14 & & 16 & \\
\hline & Poor & $17(25.8)$ & 8 & & 8 & & 11 & & 12 & \\
\hline & Unknown & $5(7.6)$ & 2 & & 3 & & 3 & & 3 & \\
\hline \multirow{3}{*}{$\begin{array}{l}\text { Perineural } \\
\text { invasion }\end{array}$} & Negative & $28(42.4)$ & 6 & 0.016 & 5 & 0.001 & 7 & 0.001 & 9 & 0.004 \\
\hline & Positive & $27(40.9)$ & 13 & & 16 & & 18 & & 19 & \\
\hline & Unknown & $11(16.7)$ & 3 & & 4 & & 5 & & 6 & \\
\hline \multirow{3}{*}{$\begin{array}{l}\text { Lymphatic } \\
\text { invasion }\end{array}$} & Negative & $23(34.8)$ & 4 & 0.012 & 3 & 0.002 & 4 & 0.001 & 7 & 0.011 \\
\hline & Positive & $34(51.5)$ & 15 & & 17 & & 20 & & 21 & \\
\hline & Unknown & $9(13.6)$ & 3 & & 5 & & 6 & & 6 & \\
\hline \multirow{3}{*}{$\begin{array}{l}\text { Vascular } \\
\text { invasion }\end{array}$} & Negative & $32(48.5)$ & 8 & 0.041 & 9 & 0.102 & 10 & 0.015 & 15 & 0.319 \\
\hline & Positive & $20(30.3)$ & 10 & & 10 & & 13 & & 11 & \\
\hline & Unknown & $14(21.2)$ & 4 & & 6 & & 7 & & 8 & \\
\hline Preoperative & $\geq 37 \mathrm{U} / \mathrm{ml}$ & $18(27.3)$ & 11 & 0.006 & 10 & 0.121 & 14 & 0.006 & 13 & 0.056 \\
\hline \multirow[t]{2}{*}{ CA 19-9 } & $<37 \mathrm{U} / \mathrm{ml}$ & $35(53.0)$ & 8 & & 11 & & 11 & & 16 & \\
\hline & Unknown & $13(19.7)$ & 3 & & 4 & & 5 & & 5 & \\
\hline \multirow{3}{*}{$\begin{array}{l}\text { Postoperative } \\
\text { CA 19-9 }\end{array}$} & $\geq 37 \mathrm{U} / \mathrm{ml}$ & $10(15.2)$ & 9 & $<0.001$ & 7 & 0.006 & 10 & $<0.001$ & 10 & $<0.001$ \\
\hline & $<37 \mathrm{U} / \mathrm{ml}$ & $53(80.3)$ & 13 & & 17 & & 19 & & 21 & \\
\hline & Unknown & $3(4.5)$ & 0 & & 1 & & 1 & & 3 & \\
\hline \multirow{2}{*}{$\begin{array}{l}\text { Adjuvant } \\
\text { treatment }\end{array}$} & Yes & $29(43.9)$ & 12 & 0.370 & 15 & 0.124 & 18 & 0.067 & 17 & 0.755 \\
\hline & No & $37(56.1)$ & 10 & & 10 & & 12 & & 17 & \\
\hline Adjuvant & Yes & $19(28.8)$ & 7 & 0.973 & 10 & 0.237 & 12 & 0.191 & 11 & 0.962 \\
\hline chemotherapy & No & $47(71.2)$ & 15 & & 15 & & 18 & & 23 & \\
\hline Adjuvant & Yes & $11(16.7)$ & 5 & 0.358 & 5 & 0.735 & 6 & 0.595 & 6 & 0.969 \\
\hline radiotherapy & No & $55(83.3)$ & 17 & & 20 & & 24 & & 28 & \\
\hline NLR & $<5.6$ & $33(50.0)$ & 9 & 0.320 & 13 & 0.777 & 14 & 0.634 & 17 & 0.838 \\
\hline & $\geq 5.6$ & $33(50.0)$ & 13 & & 12 & & 16 & & 17 & \\
\hline PLR & $<162$ & $33(50.0)$ & 7 & 0.037 & 10 & 0.231 & 11 & 0.059 & 14 & 0.108 \\
\hline & $\geq 162$ & $33(50.0)$ & 15 & & 15 & & 19 & & 20 & \\
\hline
\end{tabular}

NLR: Neutrophil to lymphocyte ratio; PLR: platelet to lymphocyte ratio. Patients with unknown information were not included in statistical analyses. Statistically significant $p$-values are shown in bold.

\section{Discussion}

Poor prognosis after curative resection of GBC necessitates adjuvant treatment. However, because of the low incidence of GBC, the pattern of recurrences is not well defined and optimal adjuvant modality has not yet been determined. Jarnagin et al. reported the pattern of initial recurrences after surgical resection in GBC (11). After a median follow-up 24 months, $66 \%$ of patients with GBC developed tumor recurrences. Of these recurrences, DM developed in $72 \%$ and 
in vivo $36: 961-968$ (2022)

Table II. Multivariate analysis of locoregional recurrence-free (LRRFS), distant metastasis-free (DMFS), disease-free (DFS) and overall (OS) survival in the whole patient cohort.

\begin{tabular}{|c|c|c|c|c|c|c|c|c|c|}
\hline \multirow[b]{2}{*}{ Variable } & \multirow[b]{2}{*}{ Comparison } & \multicolumn{2}{|l|}{ LRRFS } & \multicolumn{2}{|l|}{ DMFS } & \multicolumn{2}{|l|}{ DFS } & \multicolumn{2}{|l|}{ OS } \\
\hline & & HR (95\% CI) & $p$-Value & HR $(95 \% \mathrm{CI})$ & $p$-Value & HR $(95 \% \mathrm{CI})$ & $p$-Value & $\operatorname{HR}(95 \% \mathrm{CI})$ & $p$-Value \\
\hline Age & $\geq 65$ vs. $<65$ Years* & $* \quad 1.41(0.44-4.53)$ & 0.566 & $0.86(0.32-2.32)$ & 0.766 & $1.32(0.49-3.52)$ & 0.581 & $1.42(0.58-3.49)$ & 0.442 \\
\hline Overall stage & III-IV vs. II* & $25.98(3.04-221.97)$ & 0.003 & $9.74(1.93-49.18)$ & 0.006 & $7.61(1.90-30.45)$ & 0.004 & $4.06(1.28-12.93)$ & ) 0.018 \\
\hline $\begin{array}{l}\text { Residual disease } \\
\text { status }\end{array}$ & $\mathrm{R} 1$ vs. $\mathrm{R} 0 *$ & $5.30(1.73-16.22)$ & 0.003 & $2.26(0.72-7.11)$ & 0.163 & $3.53(1.21-10.35)$ & 0.021 & $4.08(1.38-12.07)$ & ) 0.011 \\
\hline PLR & $\geq 162$ vs. $<162 *$ & $1.15(0.41-3.26)$ & 0.787 & $1.37(0.48-3.86)$ & 0.557 & $1.38(0.53-3.64)$ & 0.511 & $1.03(0.42-2.50)$ & 0.953 \\
\hline $\begin{array}{l}\text { Postoperative } \\
\text { CA 19-9 }\end{array}$ & $\begin{array}{c}\geq 37 \mathrm{vs} \\
<37 \mathrm{U} / \mathrm{ml}^{*}\end{array}$ & $3.60(1.32-9.83)$ & 0.013 & $2.82(1.05-7.62)$ & 0.040 & $3.26(1.32-8.02)$ & 0.010 & $4.92(1.90-12.73)$ & 0.001 \\
\hline $\begin{array}{l}\text { Adjuvant } \\
\text { treatment }\end{array}$ & No vs. yes* & $2.21(0.74-6.61)$ & 0.158 & $1.31(0.49-3.50)$ & 0.590 & $1.20(0.45-3.19)$ & 0.715 & $1.92(0.73-5.05)$ & 0.183 \\
\hline
\end{tabular}

CI: Confidence interval; HR: hazard ratio; PLR: platelet to lymphocyte ratio. Patients with unknown information were not included in statistical analyses. Statistically significant $p$-values are shown in bold. *Reference.

isolated LRRs occurred in $15 \%$ of patients. Based on these, the authors suggested a limited role for adjuvant RT in GBC. Another study by Kim et al. also reported patterns of initial recurrences in 70 patients with GBC who underwent curative resection (4). In their study, no patients received adjuvant RT and tumor recurrences developed in $58.5 \%$ of patients after a median follow-up of 23 months. LRRs as initial failure developed in $41.4 \%$ of recurrences and DM with or without LRRs in $40 \%$. On multivariate analysis for LRR, $\geq \mathrm{T} 2$ disease and microscopic residual disease were significant prognostic factors and a possible role of adjuvant RT was suggested in patients with these risk factors. In our study, initial recurrences were locoregional in $30.0 \%$, distant in $23.3 \%$ and locoregional with concomitant DM in $46.7 \%$. Therefore, DM was not the dominant type of recurrence and efforts to reduce both LRRs and DM are necessary to improve the prognosis of patients with GBC.

Previous studies investigated the role of adjuvant RT after curative surgical resection for GBC, but the results are not conclusive. Park et al. evaluated the outcome of adjuvant treatment in patients with GBC who underwent complete resection (R0) and concluded that adjuvant treatment was not indicated in patients R0 resected for stage II disease (12). Similar results were reported by Go et al. (13). In their study, patients receiving adjuvant treatment had more adverse factors compared with those undergoing surgery alone but there were no significant differences in DFS and OS between the two groups after propensity-score matching. The authors suggested no need for adjuvant treatment in R0 resected GBC. However, in a study by $\operatorname{Im}$ et al. evaluating 272 patients with GBC, a significant number of patients still experienced recurrence (isolated LRRs in 14\% of patients, DM in $15 \%$ and both LRRs with DM in $7 \%$ ) after R0 resection and the risk factors for LRRs were investigated (14). In their results, lymphovascular invasion, T3 disease and lymph node metastasis were significant risk factors for LRRs and they suggested that patients with these risk factors might benefit from additional treatment. Another study by Jeong et al. reported the outcome of adjuvant RT in 86 patients undergoing surgical resection of GBC with curative intent (15). In their study, although $16 \%$ of patients had R1 resection, isolated LRRs developed in only $8 \%$ of patients, which suggest the benefit of adjuvant RT. In a study by Lim et al., which include 279 patients with GBC undergoing surgical resection, R0 resection was achieved in $58.8 \%$ of patients (16). The extent of surgical resection, histological differentiation and resection margin status were prognostic factors, and in patients with an involved resection margin, adding adjuvant RT improved the survival. Therefore, adjuvant RT can provide additional benefit in selected patients undergoing curative resection.

The role of adjuvant CRT or chemotherapy for GBC after surgical resection is also controversial but recent studies have reported the benefit of adjuvant treatment. A prospective randomized trial evaluated the role of adjuvant chemotherapy in GBC (17). In that study, patients with pancreaticobiliary tract carcinomas were randomized to either adjuvant chemotherapy or surgery alone. Adjuvant chemotherapy improved OS and DFS in patients with GBC treated with noncurative resection. In a phase II SWOG S0809 trial, the efficacy and tolerability of adjuvant chemotherapy followed by CRT was evaluated (18). The results showed improved outcome compared with historical data and, notably, no isolated LRR developed in patients after a median follow-up of 35 months. Gold et al. reported the outcome of concurrent CRT with 5-FU chemotherapy in patients with R0 resection of GBC (19). In their study, no prognostic factors were found to predict the survival of the patients, but patients receiving adjuvant CRT had more advanced stage and pathology other than adenocarcinoma. 
Table III. Univariate analysis of locoregional recurrence-free (LRRFS), distant metastasis-free (DMFS), disease-free (DFS) and overall (OS) survival in patients with stage III-IV disease $(n=40)$.

\begin{tabular}{|c|c|c|c|c|c|c|c|c|c|c|}
\hline \multirow[b]{2}{*}{ Variables } & \multirow[b]{2}{*}{ Subgroup } & \multirow[b]{2}{*}{$\mathrm{n}(\%)$} & \multicolumn{2}{|c|}{ LRRFS } & \multicolumn{2}{|c|}{ DMFS } & \multicolumn{2}{|c|}{ DFS } & \multicolumn{2}{|c|}{ OS } \\
\hline & & & Event (n) & $p$-Value & Event (n) & $p$-Value & Event (n) & $p$-Value & Event (n) & $p$-Value \\
\hline \multirow[t]{2}{*}{ Age } & $<65$ Years & $19(47.5)$ & 8 & 0.037 & 11 & 0.615 & 11 & 0.087 & 11 & 0.073 \\
\hline & $\geq 65$ Years & $21(52.5)$ & 13 & & 11 & & 15 & & 16 & \\
\hline \multirow[t]{2}{*}{ Gender } & Male & $16(40.0)$ & 5 & 0.191 & 10 & 0.541 & 12 & 0.509 & 10 & 0.926 \\
\hline & Female & $24(60.0)$ & 14 & & 12 & & 14 & & 17 & \\
\hline \multirow[t]{3}{*}{ T-Stage } & pT2 & $12(30.0)$ & 6 & 0.544 & 6 & 0.744 & 7 & 0.577 & 7 & 0.083 \\
\hline & pT3 & $26(65.0)$ & 14 & & 15 & & 18 & & 18 & \\
\hline & pT4 & $2(5.0)$ & 1 & & 1 & & 1 & & 2 & \\
\hline \multirow[t]{3}{*}{ N-Stage } & pNO & $10(25.0)$ & 4 & 0.045 & 5 & 0.080 & 6 & 0.152 & 7 & 0.125 \\
\hline & $\mathrm{pN} 1$ & $26(65.0)$ & 13 & & 13 & & 16 & & 16 & \\
\hline & $\mathrm{pN} 2$ & $4(10.0)$ & 4 & & 4 & & 4 & & 4 & \\
\hline \multirow[t]{2}{*}{ Overall stage } & III & $35(87.5)$ & 17 & 0.024 & 18 & 0.056 & 22 & 0.107 & 22 & 0.009 \\
\hline & IV & $5(12.5)$ & 4 & & 4 & & 4 & & 5 & \\
\hline \multirow{3}{*}{$\begin{array}{l}\text { Residual disease } \\
\text { status }\end{array}$} & R0 & $30(75.0)$ & 14 & 0.006 & 16 & 0.195 & 18 & 0.024 & 19 & 0.070 \\
\hline & $\mathrm{R} 1$ & $7(17.5)$ & 6 & & 5 & & 6 & & 6 & \\
\hline & Unknown & $3(7.5)$ & 2 & & 1 & & 2 & & 2 & \\
\hline \multirow{4}{*}{$\begin{array}{l}\text { Tumor } \\
\text { differentiation }\end{array}$} & Well & $2(5.0)$ & 2 & 0.989 & 8 & 0.842 & 2 & 0.792 & 2 & 0.655 \\
\hline & Moderate & $18(45.0)$ & 9 & & 9 & & 10 & & 10 & \\
\hline & Poor & $16(40.0)$ & 8 & & 4 & & 11 & & 12 & \\
\hline & Unknown & $4(10.0)$ & 2 & & 3 & & 3 & & 3 & \\
\hline \multirow[t]{3}{*}{ Perineural invasion } & Negative & $12(30.0)$ & 6 & 0.398 & 7 & 0.100 & 7 & 0.186 & 6 & 0.158 \\
\hline & Positive & $20(50.0)$ & 12 & & 6 & & 12 & & 16 & \\
\hline & Unknown & $8(20.0)$ & 3 & & 9 & & 4 & & 5 & \\
\hline \multirow[t]{3}{*}{ Lymphatic invasion } & Negative & $7(17.5)$ & 4 & 0.663 & 3 & 0.336 & 4 & 0.356 & 4 & 0.529 \\
\hline & Positive & $26(65.0)$ & 14 & & 15 & & 17 & & 18 & \\
\hline & Unknown & $7(17.5)$ & 3 & & 4 & & 5 & & 5 & \\
\hline \multirow[t]{3}{*}{ Vascular invasion } & Negative & $15(37.5)$ & 8 & 0.462 & 8 & 0.600 & 9 & 0.295 & 11 & 0.807 \\
\hline & Positive & $14(35.0)$ & 9 & & 9 & & 11 & & 9 & \\
\hline & Unknown & $11(27.5)$ & 4 & & 5 & & 6 & & 7 & \\
\hline Preoperative & $\geq 37 \mathrm{U} / \mathrm{ml}$ & $15(37.5)$ & 10 & 0.149 & 9 & 0.826 & 12 & 0.335 & 11 & 0.545 \\
\hline \multirow{2}{*}{ CA 19-9 } & $<37 \mathrm{U} / \mathrm{ml}$ & $21(52.5)$ & 8 & & 11 & & 11 & & 13 & \\
\hline & Unknown & $4(10.0)$ & 3 & & 2 & & 3 & & 3 & \\
\hline Postoperative & $\geq 37 \mathrm{U} / \mathrm{ml}$ & $9(22.5)$ & 8 & 0.029 & 7 & 0.109 & 9 & 0.037 & 9 & 0.004 \\
\hline \multirow[t]{2}{*}{ CA $19-9$} & $<37 \mathrm{U} / \mathrm{ml}$ & $28(70.0)$ & 13 & & 14 & & 16 & & 15 & \\
\hline & Unknown & $3(7.5)$ & 0 & & 1 & & 1 & & & \\
\hline \multirow[t]{2}{*}{ Adjuvant treatment } & Yes & $25(62.5)$ & 12 & 0.029 & 13 & 0.093 & 16 & 0.096 & 15 & 0.005 \\
\hline & No & $15(37.5)$ & 9 & & 9 & & 10 & & 12 & \\
\hline \multirow[t]{2}{*}{ Adjuvant chemotherapy } & Yes & $16(40.0)$ & 7 & 0.064 & 8 & 0.274 & 10 & 0.242 & 9 & 0.040 \\
\hline & No & $24(60.0)$ & 14 & & 14 & & 16 & & 18 & \\
\hline \multirow[t]{2}{*}{ Adjuvant radiotherapy } & Yes & $10(25.0)$ & 5 & 0.666 & 5 & 0.439 & 6 & 0.449 & 6 & 0.439 \\
\hline & No & $30(75.0)$ & 16 & & 17 & & 20 & & 21 & \\
\hline
\end{tabular}

Patients with unknown information were not included in statistical analyses. Statistically significant $p$-values are shown in bold.

After adjusting for adverse factors, adjuvant CRT was a significant prognostic factor for OS. Another study reported the benefit of adjuvant CRT by investigating data from the Surveillance, Epidemiology, and End Results Medicare database (20). As a result, adjuvant CRT was shown to have improved the survival of patients with $\geq \mathrm{T} 2$ or $\mathrm{N} 1$ disease, and CRT was more effective than chemotherapy alone in all subsets of patients. Similarly, in another study by Kim et al., which evaluated the role of adjuvant CRT and chemotherapy, the authors showed improved LRRFS, DFS and OS in the adjuvant CRT group compared to adjuvant chemotherapy and the no adjuvant treatment group in patients with lymph node metastasis (21). An earlier multi-institutional study by Kim et al. reported the effect of adjuvant chemotherapy or CRT in patients who underwent resection for GBC (22). They showed that patients with adverse factors such as T3 or $\mathrm{T} 4$ disease, lymph node metastasis and $\mathrm{R} 1$ resection benefited from adjuvant chemotherapy or CRT.

In our study, the risk factors predicting poor outcomes of patients with GBC were consistent with those of previous 
Table IV. Multivariate analysis of locoregional recurrence-free (LRRFS), distant metastasis-free (DMFS), disease-free (DFS) and overall (OS) survival in patients with stage III-IV disease.

\begin{tabular}{|c|c|c|c|c|c|c|c|c|c|}
\hline \multirow[b]{2}{*}{ Variable } & \multirow[b]{2}{*}{ Comparison } & \multicolumn{2}{|l|}{ LRRFS } & \multicolumn{2}{|l|}{ DMFS } & \multicolumn{2}{|l|}{ DFS } & \multicolumn{2}{|l|}{ OS } \\
\hline & & $\operatorname{HR}(95 \% \mathrm{CI})$ & $p$-Value & HR $(95 \%$ CI $)$ & $p$-Value & HR $(95 \%$ CI $)$ & $p$-Value & $\operatorname{HR}(95 \% \mathrm{CI})$ & $p$-Value \\
\hline Age & $\geq 65$ vs. $<65$ Years* & $1.75(0.56-5.45)$ & 0.337 & $0.93(0.35-2.48)$ & 0.888 & $1.38(0.51-3.74)$ & 0.522 & $1.06(0.40-2.80)$ & 0.899 \\
\hline Overall stage & IV $v s . \mathrm{III}^{*}$ & $3.44(0.86-13.80)$ & 0.081 & $1.97(0.53-7.26)$ & 0.309 & $1.97(0.54-7.12)$ & 0.302 & $3.78(0.94-15.18)$ & 0.061 \\
\hline $\begin{array}{l}\text { Residual } \\
\text { disease status }\end{array}$ & $\mathrm{R} 1$ vs. $\mathrm{R} 0 *$ & $5.56(1.81-17.08)$ & 0.003 & $2.60(0.83-8.16)$ & 0.101 & $4.17(1.41-12.36)$ & 0.010 & $4.64(1.59-13.59)$ & 0.005 \\
\hline $\begin{array}{l}\text { Postoperative } \\
\text { CA 19-9 }\end{array}$ & $\begin{array}{c}\geq 37 \mathrm{vs} \\
<37 \mathrm{U} / \mathrm{ml}^{*}\end{array}$ & $2.25(0.74-6.87)$ & 0.155 & $2.37(0.77-7.27)$ & 0.132 & $2.42(0.88-6.71)$ & 0.087 & $2.57(0.77-8.57)$ & 0.126 \\
\hline $\begin{array}{l}\text { Adjuvant } \\
\text { treatment }\end{array}$ & No vs. yes* & $2.43(0.84-7.07)$ & 0.102 & $1.80(0.67-4.84)$ & 0.243 & $1.66(0.63-4.33)$ & 0.305 & $3.50(1.24-9.90)$ & 0.018 \\
\hline
\end{tabular}

CI: Confidence interval; HR: hazard ratio. Patients with unknown information were not included in statistical analyses. Statistically significant $p$ values are shown in bold. *Reference.
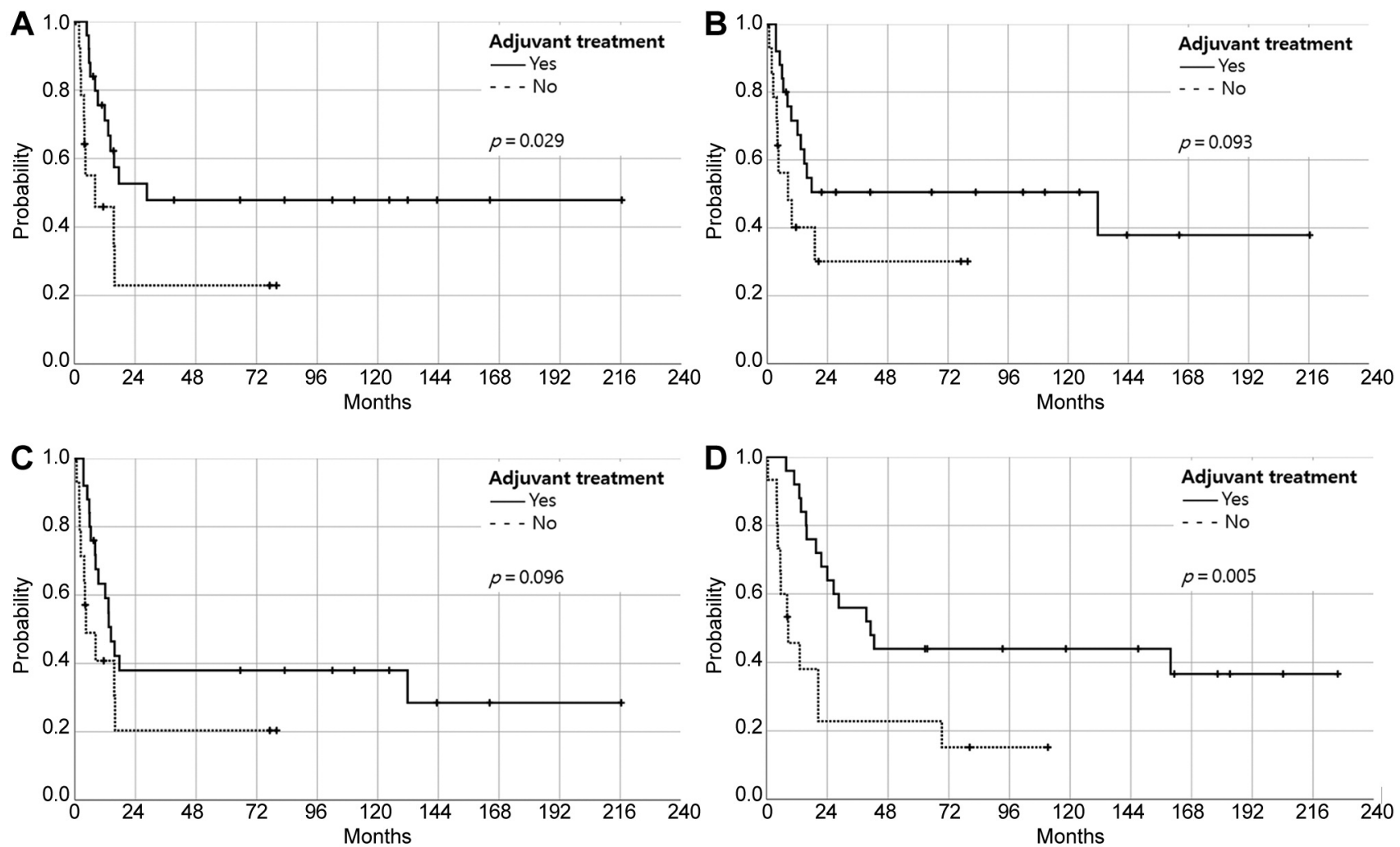

Figure 2. Locoregional recurrence-free (A), distant metastasis-free (B), disease-free (C), and overall (D) survival curves according to adjuvant treatment for the subgroup with stage III-IV gallbladder cancer $(n=40)$.

studies. Patients with advanced stage, higher postoperative CA 19-9 level, and R1 resection had poor prognosis. However, our study failed to demonstrate the benefit of adding adjuvant treatment after surgical resection, whether RT or chemotherapy; the benefit of adjuvant treatment might be underestimated because patients' characteristics and administered treatments were largely heterogeneous, which came from the small, retrospective study design. Of note, most studies we referenced above showed the benefit of adjuvant treatment in high-risk patients. Our subgroup analysis involving patients with stage III-IV disease showed similar survival benefits from adjuvant treatment. Further studies with 
larger numbers of patients with homogeneous groups are needed to define the subset of patients who might benefit from adjuvant treatment after surgical resection of GBC.

\section{Conflicts of Interest}

The Authors fully declare that there are no financial or other potential conflicts of interest.

\section{Authors' Contributions}

Younghee Park drafted the article. Kiryun Kim collected the data. Hae Jin Park designed the study and analyzed the data. Ha-Jung Chun and Dongho Choi participated in the interpretation of results. Kyubo Kim revised the article. All Authors read and approved the final article.

\section{Acknowledgements}

Kiryun Kim was a trainee of the Medical Scientist Training Program at Hanyang University College of Medicine.

\section{References}

1 Wi Y, Woo H, Won YJ, Jang JY and Shin A: Trends in gallbladder cancer incidence and survival in Korea. Cancer Res Treat 50(4): 1444-1451, 2018. PMID: 29370591. DOI: 10.4143/ crt.2017.279

2 Jung KW, Won YJ, Hong S, Kong HJ and Lee ES: Prediction of cancer incidence and mortality in Korea, 2020. Cancer Res Treat 52(2): 351-358, 2020. PMID: 32178488. DOI: 10.4143/crt. 2020.203

3 Kayahara M, Nagakawa T, Nakagawara H, Kitagawa $H$ and Ohta T: Prognostic factors for gallbladder cancer in Japan. Ann Surg 248(5): 807-814, 2008. PMID: 18948808. DOI: 10.1097/ SLA.0b013e31818a1561

4 Kim TG: Patterns of initial failure after resection for gallbladder cancer: implications for adjuvant radiotherapy. Radiat Oncol J 35(4): 359-367, 2017. PMID: 29249117. DOI: 10.3857/roj.2017.00388

5 Margonis GA, Gani F, Buettner S, Amini N, Sasaki K, Andreatos N, Ethun CG, Poultsides G, Tran T, Idrees K, Isom CA, Fields RC, Krasnick B, Weber SM, Salem A, Martin RC, Scoggins C, Shen P, Mogal HD, Schmidt C, Beal E, Hatzaras I, Shenoy R, Maithel SK and Pawlik TM: Rates and patterns of recurrence after curative intent resection for gallbladder cancer: a multiinstitution analysis from the US Extra-hepatic Biliary Malignancy Consortium. HPB (Oxford) 18(11): 872-878, 2016. PMID: 27527802. DOI: 10.1016/j.hpb.2016.05.016

6 Kim K, Chie EK, Jang JY, Kim SW, Han SW, Oh DY, Im SA, Kim TY, Bang YJ and Ha SW: Postoperative chemoradiotherapy for gallbladder cancer. Strahlenther Onkol 188(5): 388-392, 2012. PMID: 22402869. DOI: 10.1007/s00066-012-0074-7

7 Cho SY, Kim SH, Park SJ, Han SS, Kim YK, Lee KW, Lee WJ, Woo SM and Kim TH: Adjuvant chemoradiation therapy in gallbladder cancer. J Surg Oncol 102(1): 87-93, 2010. PMID: 20578085. DOI: $10.1002 /$ jso. 21544

8 Kim BH, Kwon J, Chie EK, Kim K, Kim YH, Seo DW, Narang AK and Herman JM: Adjuvant chemoradiotherapy is associated with improved survival for patients with resected gallbladder carcinoma: a systematic review and meta-analysis. Ann Surg Oncol 25(1): 255-264, 2018. PMID: 29079926. DOI: 10.1245/ s10434-017-6139-1

9 Nakamura M, Nakashima H, Abe T, Ensako T, Yoshida K and Hino K: Gemcitabine-based adjuvant chemotherapy for patients with advanced gallbladder cancer. Anticancer Res 34(6): 31253129, 2014. PMID: 24922682.

10 Amin MB, Edge SB, Greene FL, Byrd DR, Brookland RK, Washington MK, Gershenwald JE, Compton CC, Hess KR and Sullivan DC: AJCC Cancer Staging Manual, Eigth Edition. Springer International Publishing, 2018.

11 Jarnagin WR, Ruo L, Little SA, Klimstra D, D'Angelica M, DeMatteo RP, Wagman R, Blumgart LH and Fong Y: Patterns of initial disease recurrence after resection of gallbladder carcinoma and hilar cholangiocarcinoma: implications for adjuvant therapeutic strategies. Cancer 98(8): 1689-1700, 2003. PMID: 14534886. DOI: $10.1002 /$ cncr.11699

12 Park HS, Lim JY, Yoon DS, Park JS, Lee DK, Lee SJ, Choi HJ, Song SY, Lee WJ and Cho JY: Outcome of adjuvant therapy for gallbladder cancer. Oncology 79(3-4): 168-173, 2010. PMID: 21212704. DOI: $10.1159 / 000322914$

13 Go SI, Kim YS, Hwang IG, Kim EY, Oh SY, Ji JH, Song HN, Park SH, Park JO and Kang JH: Is there a role for adjuvant therapy in $\mathrm{R} 0$ resected gallbladder cancer?: A propensity scorematched analysis. Cancer Res Treat 48(4): 1274-1285, 2016. PMID: 26875193. DOI: 10.4143/crt.2015.502

14 Im JH, Lee WJ, Kang CM, Hwang HK and Seong J: Prognostic factors and patterns of loco-regional failure in patients with R0 resected gallbladder cancer. HPB (Oxford) 22(8): 1168-1173, 2020. PMID: 31784211. DOI: 10.1016/j.hpb.2019.10.2447

15 Jeong Y, Park JH, Lee YJ, Park KM, Hwang S, Chang HM, Kim $\mathrm{KP}$, Yoon SM, Jung NH and Kim JH: Postoperative radiotherapy for gallbladder cancer. Anticancer Res 34(10): 5621-5629, 2014. PMID: 25275065.

16 Lim H, Seo DW, Park DH, Lee SS, Lee SK, Kim MH and Hwang S: Prognostic factors in patients with gallbladder cancer after surgical resection: analysis of 279 operated patients. J Clin Gastroenterol 47(5): 443-448, 2013. PMID: 23188077. DOI: 10.1097/MCG.0b013e3182703409

17 Takada T, Amano H, Yasuda H, Nimura Y, Matsushiro T, Kato $\mathrm{H}$, Nagakawa T, Nakayama $\mathrm{T}$ and Study Group of Surgical Adjuvant Therapy for Carcinomas of the Pancreas and Biliary Tract: Is postoperative adjuvant chemotherapy useful for gallbladder carcinoma? A phase III multicenter prospective randomized controlled trial in patients with resected pancreaticobiliary carcinoma. Cancer 95(8): 1685-1695, 2002. PMID: 12365016. DOI: $10.1002 / \mathrm{cncr} .10831$

18 Ben-Josef E, Guthrie KA, El-Khoueiry AB, Corless CL, Zalupski MM, Lowy AM, Thomas CR Jr, Alberts SR, Dawson LA, Micetich KC, Thomas MB, Siegel AB and Blanke CD: SWOG S0809: A phase II intergroup trial of adjuvant capecitabine and gemcitabine followed by radiotherapy and concurrent capecitabine in extrahepatic cholangiocarcinoma and gallbladder carcinoma. J Clin Oncol 33(24): 2617-2622, 2015. PMID: 25964250. DOI: 10.1200/JCO.2014.60.2219

19 Gold DG, Miller RC, Haddock MG, Gunderson LL, Quevedo F, Donohue JH, Bhatia S and Nagorney DM: Adjuvant therapy for gallbladder carcinoma: the Mayo Clinic Experience. Int J Radiat Oncol Biol Phys 75(1): 150-155, 2009. PMID: 19297105. DOI: $10.1016 /$ j.jirobp.2008.10.052 
20 Wang SJ, Lemieux A, Kalpathy-Cramer J, Ord CB, Walker GV, Fuller CD, Kim JS and Thomas CR Jr: Nomogram for predicting the benefit of adjuvant chemoradiotherapy for resected gallbladder cancer. J Clin Oncol 29(35): 4627-4632, 2011. PMID: 22067404. DOI: 10.1200/JCO.2010.33.8020

21 Kim TH, Woo SM, Lee WJ, Oh ES, Youn SH, Moon SH, Kim SS, Han SS, Park SJ and Kim DY: Benefit of adjuvant chemoradiotherapy in resected gallbladder carcinoma. Sci Rep 9(1): 11770, 2019. PMID: 31409811. DOI: 10.1038/s41598-01948099-Z

22 Kim Y, Amini N, Wilson A, Margonis GA, Ethun CG, Poultsides G, Tran T, Idrees K, Isom CA, Fields RC, Krasnick B, Weber SM, Salem A, Martin RC, Scoggins C, Shen P, Mogal HD,
Schmidt C, Beal E, Hatzaras I, Shenoy R, Cardona K, Maithel SK and Pawlik TM: Impact of chemotherapy and external-beam radiation therapy on outcomes among patients with resected gallbladder cancer: a multi-institutional analysis. Ann Surg Oncol 23(9): 2998-3008, 2016. PMID: 27169772. DOI: 10.1245/ s10434-016-5262-8

Received November 17, 2021

Revised December 15, 2021

Accepted December 18, 2021 